\title{
Modeling the relationship between the perceived negotiation styles and conflict management among physical education experts
}

\author{
Mojtaba HASANNEJAD, Ali ZAREI, Farideh ASHRAFGANJOUEI
}

Department of Sport Management, Tehran Central Branch, Islamic Azad University, Tehran, Iran.

Address correspondence to M. Hasannejad, e-mail: mojtabahassannejad@gmail.com

\begin{abstract}
This study aims to modeling the relationship between the perception of negotiation and conflict management styles among physical education experts. The method of study is descriptive - correlation and it has conducted as a survey and a field study in terms of methodology. 217 out of 248 total number of distributed questionnaires were found suitable as the sample. Standard questionnaire of negotiation styles designed by Pierre was used as a measuring tool. Also, testing the conflict management strategies, standard questionnaire of Robbins was used. Using the factor analysis, the validity of the questionnaires was confirmed by a group of professors. And, reliability of the questionnaires was estimated with test-retest coefficient. The evaluations of the both negotiation styles and conflict management questionnaires are 0.78 and 0.73 , respectively. Assessing the variables of the research, statistical tests such as Pearson correlation, regression and structural equation modeling were applied. The results showed that there is a significant relationship between the styles of negotiation and conflict management. Also, the negotiation styles (analytical, normative and realistic) were able to account for variances related to conflict management. Furthermore, structural equation modeling confirmed the relationship between components of negotiation with conflict management. The findings of this research indicate that the conflicts within the organization will be properly managed, if the knowledge about negotiating skills and its styles increases. Proper communication through negotiations would result in reducing the destructive conflict in organizations.
\end{abstract}

Keywords: Conflict management, negotiation, physical education experts, sports management.

\section{INTRODUCTION}

An organization is a collection of individuals and groups, so its achievement and success is interwoven with finding a way or means to direct the energy and efforts of different working groups towards the organization's overall objectives. It is possible that various groups follow other aims or they may find their interest in some other sources. This in general would result in the interaction or conflict of interest in the organization. In that case, the interest of the organization may be diverted and managers need to find a solution to tackle the problem.
The most recent studies on the situation of conflict among high and middle level managers in an organization demonstrate that managing conflict in higher levels of directing of an organization is as important as- and in some situations even more important than- planning, organizing, communicating, motivation and decision-making. The "average" manager studied spent 20 percent of his or her time in managing conflict (21). Twenty-five executives have been asked in a survey aimed at grading the factors of their career success. The most influential factor was the ability to deal with conflict or managing the conflict recognized as the factor playing the most important role in their success. Thus, the issue of conflict has 
indeed shaped public attitudes, especially managers and leaders' outlook, more than any other factors (4). People's general attitude and public opinions consider that conflict is a break or barrier holds against the success; though, it is proven wrong and it has been recognized that conflict is not only necessary, but also a productive factor in the organizational structure which help moving the organization forward towards the determined goals. In other words, if the manager recognizes the conflicts in the organization timely, he would be able to employ the appropriate conflict management techniques and this can help to create fair competition resulting in an accelerated move towards organizational objectives. Otherwise, since the conflict is an issue which people are consciously aware of, achieving the objectives of the organization would not be at ease (1).

In the meantime, negotiation as an efficient tool to create effective communication techniques is used to solve the problems and conflicts in organizations. Negotiation is a process of communication in which the parties aim to send a message to the other side and influence each other. Thus, power in negotiation lies in the ability to favorably affect someone else's decision. Some assume that because threats of physical force exert influence, the ability to make such threats is the essence of negotiating power (5). Since we live in the world of communications, negotiation is considered as a communicative event and lack of communicative skills can be a barrier to success and progress in various fields (24). Accordingly, negotiate and regulate the exchange of thoughts and feelings is a way to achieve understanding and results in peace and tranquility (13). Problems solving in the organization require special skills and expertise. A weak negotiator may direct the organization towards disorder and failure. Since organizations are increasingly cooperative, executives' familiarity with the concepts of negotiation would be imperative (5). Since co-managed organizations are increasingly growing, the most important tool for the sophisticated and increasing means of communication today is applying the techniques and the art of negotiation.

Rezaeian (20), Mir Masoudi (11), Veismoradi et al. (28) categorized the application of negotiation styles among managers in an order from the most to the least degree of importance. In their studies, the negotiation styles were ranked as realistic, analytic, normative and intuitive. Turani et al. (27) concluded that the Matrons most often use such negotiating styles as realistic, analytic and normative due to the existing conditions, although the intuitive style is the exact style of negotiation which is used by all nurses in hospitals in Bushehr Province. Using the Friedman test, Rahimi (18), Panahi (17) and Torabi (25) categorized and prioritized the managers' negotiating styles in which realistic style has ranked at the first place. In fact, the realists have traits that make them more successful negotiators.

Nekoeimoghadam (15) conducted a study and found that the conflict management strategies used in hospitals in Kerman Province are avoidance, solutionfocused and control strategies, respectively. Torabipour (25) in a study concluded that people in terms of conflict management strategies chose 49.7 percent of avoidance strategy while 44.7 percent of control strategy and 5.7 percent of solution-oriented strategies were considered. Farahani (3) conducted a study among hospital managers at high and middle levels to determine what percentage of conflict management strategies are applied. He found that managers considered 4.2 percent of the conflict avoidance strategy, 50 percent of solution-oriented strategy and 45.8 percent of the control strategy.

Dehghani et al. (2) found that the solution-focused strategy $(44 \%)$ is the frequently used methodology to deal with the conflict. The findings also showed that there is a significant relationship between compatibility with solution-focused strategy and control strategy; conscience with solution-focused strategy; and avoidance strategy and openness to experience with control strategy. There is no significant relationship between other personality traits and conflict management strategies. Yo ti Yo (29) compared the cultural factors of negotiation styles and concluded that Brazilian negotiators often prefer to use the intuitive style while Russians tend to use analytical style. Indian counterparts prefer the realistic style and Chinese negotiators desire normative strategy as their dominant style. Mehri \& Moharramzadeh (10) indicated that there is a significant difference between the compromising styles of managers and staff and the typical compromising style used by employees is much more than managers; although, there is no significant difference between the style of competition, 
cooperation and avoidance between managers and employees.

Saatchian (22) concluded that solution-focused strategy is the dominant conflict management strategy which is used by athletic team trainers. Also, Shojaie (23) found out that there is a significant correlation between the impact of competitive strategy on the conflict management and quality of communication between the managers and employees. Ghaziani (6) conducted a study and the results showed that cooperation strategy and avoid approach are respectively the first and the second priorities of conflict management for physical education administrators. Oredeina (16) concluded that there is a significant relationship between leadership and conflict management in the academic environment. Raymond (19) concluded that negotiators who use the combined style of negotiation experience less stress and conflict, while those who prefer consolidation style feel more stress and tension, as well as conflict.

One of the serious problems of managers in public sectors is that they often fail to use the scientific methods of negotiation in such various issues as management, planning, cooperation and settlement of disputes, to name a few. Since the scope of government activities in all sectors of economy, culture and politics has been developed, there is a tendency among public managers to move towards the sustainable development. The appointment of proficient managers in public sectors would provide the country's progress towards sustainable development and this is possible in the shadow of updating knowledge and skills as well as the principles and techniques of negotiation (20).

Management of sports organizations, among the different types of organizations, is one of the most important, effective and sophisticated types of managed fields since the human being is the main subject of its management process. People enter the organizations, which are active in the field of physical training, need education in the physical, emotional, social, intellectual, moral and professional aspects. Physical education is one of the most important departments of Ministry of Education and it also is the most effective sport organization in the whole country.

This department is in charge of organizing and developing the official training courses aimed at upbringing a healthier generation and expertise needed in sports markets and fields.

Furthermore, there are some secondary objectives such as achieving the universal standard in physical education and encourage young people to gain sport skills. Efficiency in physical education system can be attained when training is effective and beneficial enough and this can happen when there is a right and proper situation available for staff, trainers and students. The importance of management, especially educational management in the physical education and sports training is so considerable that the art and science of managing large and small groups of people is described as the significant features of contemporary civilization in the $21^{\text {st }}$ century and this ability has turned into one of the special fields of study and research in the humanities.

The findings of several studies suggest that the schools are considered as the most important sport organizations and institutions which are responsible for training the skilled manpower. Since schools comprise the wide range of the population from box sexes and different age range, areas of education and training centers employ different attitudes in their education systems which seldom follow an identical procedure. Coaches, trainers and staff working at these centers play a crucial role to incorporate the strategies and approaches. Also, managers are responsible for increasing the productivity and avoid wasting manpower efforts to resolve the conflicts.

Various researches have concluded that the optimal management of conflict is one of the determinants of job outcomes, such as satisfaction, organizational commitment and increased organizational performance. Developing the organizational strategy in the field of the physical education at schools, department of physical education requires experts who would be able to apply the appropriate conflict management strategy. Identifying the variables affecting conflict management seems essential and requires more research. As a consequence, according to what was said, the aim of this study was to investigate the relationship between the negotiation styles and conflict management strategies among the physical education experts. Physical education professionals working in education who are responsible for managing the activities of physical education and sport in schools. The question 
is that how and to what extent different styles of negotiations would be able to influence and predict conflict management?

\section{MATERIALS \& METHODS}

This piece of research is a cross-correlation study, which is an applied research in terms of nature. The data have been gathered in a field survey and population of the study included all Physical Education experts working in different cities and regions of Iran. The sample size is an estimation of the population in which 248 people were selected by using Krejci \& Morgan (1970) table for determining sample size for research activities, educational and psychological measurement. The cluster sampling was used to divide the entire country into four zones, including north, south, east and west. Next, the determined share was assumed for the cities of each Province and then samples were calculated by randomly sampling method. Finally, 217 questionnaires were granted for the statistical analysis. Measuring tool of negotiation variable was a questionnaire with 24 entries designed by Piare (1981) comprises of four factors of negotiation styles including normative, intuitive, realistic and analytic styles. The basis of scoring in this questionnaire is the five-item Likert scoring method. 18-item questionnaire designed by Robbins (21) is the measuring tool to evaluate the components of the conflict managing strategies. Assessing the validity of the items in this study, content and construct validities were considered. The content validity was approved by a group of academic experts and the latter, construct validity, was confirmed by using the Confirmatory factor analysis technique.

Table 1 . The reliability of the variables.

\begin{tabular}{llc}
\hline Variable & Aspects & Cronbach's Alpha \\
\hline Negotiation & Normative & 0.71 \\
& Intuitive & 0.76 \\
& Realistic & 0.78 \\
& Analytical & 0.77 \\
Conflict & Avoidance & 0.80 \\
& Control & 0.79 \\
& Cooperation & 0.86 \\
\hline
\end{tabular}

The results of the construct validity obtained by using factor analysis and fitting indicators of the factor analysis confirmed the construct validity as a proper tool for the study. Ensuring the reliability of the questionnaires, first, the questionnaires were distributed among 30 people from the study population and then collected. 15 days later, the same questionnaires were distributed among the same people and the retest coefficients for the negotiation questionnaire and conflict management questionnaire were calculated 75 and 83 percent, respectively. Also, the Cronbach's alpha was used to confirm internal reliability. The results are available in Table 1 . Since the alpha value of all the variables of the research was more than 0.70 , the reliability of the questionnaire was confirmed.

Statistical analysis of research data was conducted at the both descriptive and inferential levels. Descriptive approach contained mean and standard deviation. In inferential level, the KolmogorovSmirnov test was used to analyze normal or abnormal data. Pearson correlation coefficient and the role of each of the predictor variables in explaining the variance criterion were also used. Correspondingly, Lisrel software was applied to determine the causal relationship between the dependent variable and the independent variable of the structural model.

\section{RESULTS}

Table 2 shows the mean and standard deviation of negotiation and conflict strategies and components of physical education experts in educational organizations.

Table 2. Mean and standard deviation of variables.

\begin{tabular}{lcc}
\hline Variables & Mean & SD \\
\hline Negotiation & 3.88 & 0.40 \\
Analytical & 3.57 & 0.47 \\
Normative & 3.89 & 0.51 \\
Intuitive & 3.95 & 0.52 \\
Realistic & 4.11 & 0.54 \\
Conflict strategy & 3.96 & 0.23 \\
Control & 3.94 & 0.46 \\
Cooperation & 3.98 & 0.32 \\
Avoidance & 4.06 & 0.40 \\
\hline
\end{tabular}


According to the information in Table 2, the maximum mean for negotiating styles belongs to the realistic style and the lowest mean is related to the analytical style. Among the components of the strategy of conflict, the highest and lowest means are associated with avoidance and control strategy. The evaluation of the means for both the negotiating styles and conflict strategies is 3.88 and 3.96 respectively. This evaluation indicates that the evaluated mean is at the high level. Examining the normal distribution of data, the Kolmogrov-Smirnov test was used. Since the test result equals ( $p \geq 0.05$ ), the normal distribution of data was confirmed. Therefore, the parametric statistics were used to study the variables. Table 3 shows the Pearson correlation coefficient between variables and components of the research.

Table 3. Correlation coefficient between variables.

\begin{tabular}{llcc}
\hline & Variables & $\mathrm{p}$ & Pearson Coefficient \\
\hline Conflict & Negotiation & 0.001 & 0.451 \\
Management & Analytical & 0.001 & 0.328 \\
& Normative & 0.001 & 0.451 \\
& Intuitive & 0.001 & 0.374 \\
& Realistic & 0.001 & 0.564 \\
\hline
\end{tabular}

The relationship between the predictor variables and conflict management variables through the collected data was confirmed. The results of Pearson correlation indicate that there is a significant relationship between the skill of negotiating with the conflict management as follows: negotiation $(\mathrm{r}=0.451)$, analytical style $(\mathrm{r}=0.328)$, normative style $(\mathrm{r}=0.451)$, intuitive style $(\mathrm{r}=0.374)$ and realistic style $(\mathrm{r}=0.564)$.

Table 4. Results of multiple correlation coefficients.

\begin{tabular}{ccccc}
\hline Model & $\mathrm{R}$ & $\begin{array}{c}\text { The significance } \\
\text { level }\end{array}$ & $\begin{array}{c}\text { The amount } \\
\text { of } \mathrm{F}\end{array}$ & $\begin{array}{c}\text { Adjusted } \\
\text { R-squared }\end{array}$ \\
\hline & 0.411 & 0.001 & 61.68 & 0.326 \\
\hline
\end{tabular}

Regression analysis was used to determine the effectiveness and prediction between multivariate, negotiation and conflict management skills. The result of multiple correlation coefficients in table 4 indicates that there is significant correlation between negotiation and conflict management skills among Physical education experts in Iran. Also, the coefficient of determination shows that $32 \%$ of the variance related to conflict management variable is explained by negotiating skills.

Table 5. Regression analysis and regression model.

\begin{tabular}{lcccc}
\hline Variables & $\mathrm{B}$ & $\mathrm{T}$ & Beta & $\mathrm{p}$ \\
\hline Constant factor & 1.17 & 8.59 & & 0.001 \\
Analytical style & 0.17 & 2.87 & 0.224 & 0.001 \\
Normative style & & 3.33 & 0.265 & 0.001 \\
Intuitive style & & 1.22 & 0.136 & 0.001 \\
Realistic style & & 4.51 & 0.301 & 0.001 \\
\hline
\end{tabular}

According to Table 5, the results of multivariate regression analysis show that analytical style $(\mathrm{t}=2.87$; $\mathrm{p}=0.001)$, normative style $(\mathrm{t}=3.33 ; \mathrm{p}=0.001)$ and realistic style $(t=2.87 ; p=0.001)$ are eligible to predict job engagement. Beta coefficient is used as a measure of the relative importance of variables. Thus, comparing the analytical style $(\beta=0.244)$, normative style $(\beta=265)$, intuitive style $(\beta=0.136)$ and realistic style $(\beta=0.301)$ indicates that realistic style is more important than other components found in negotiation skills.

In the next step, using structural equation modeling, causal relationship between negotiation skills and conflict management strategies was measured. Figure 1 shows the results of the relationship between negotiation skills and conflict management. The calculated coefficient determines the relationship between conflict management and negotiating skills.

In structural equation modeling to fit a number of indicators that are good indicators of the model $(2 \mathrm{X}$, $\mathrm{df}, \mathrm{P}$ value and RMSEA), respectively. The best indicator in the software LISREL df / 2 X (chi-square to degrees of freedom), which is the smaller of the three model fit (fit) better. Stock RMSEA, the mean square errors of the model. The index is based on the model errors. Limit the amount of 0.8 ; if it is below 0.8 is acceptable, if the 0.5 is pretty good .A significant number, however, is larger than 1.96 indicates 
that a strong causal effect of a stronger independent variable on the dependent variable (21).

Since the model mean-square error (0.066) is less than 0.08 and Chi-square ratio of degrees of freedom is smaller than 3, the model has a fitness and a high proportion indicating adjusted the relations of the variables seems logical according to the framework of the study.

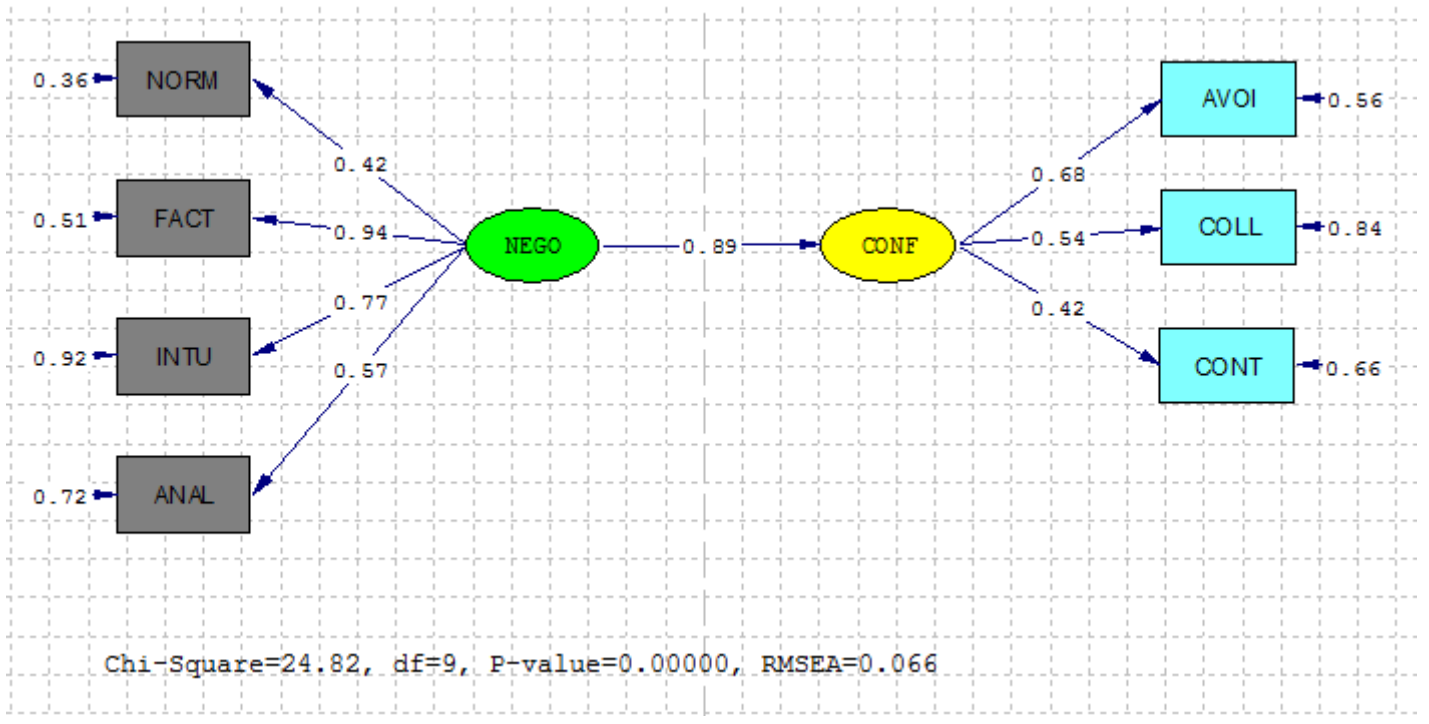

Figure 1. Structural equation modeling (standardized coefficients).

Table 6. Indicators of overall research model.

\begin{tabular}{lccc}
\hline The fit indices & Criterion & The obtained results & Model \\
\hline Chi & The less, fits better & 24.82 & - \\
Significant chi-square & P >0.05 & 0.0645 & Fit \\
Degrees of freedom & & 9 & - \\
Chi's degrees of freedom & 3 and less & 2.75 & Fit \\
RMSEA & 0.08 and less & 0.066 & Fit \\
GFI & 0.9 and more & 0.9 & Fit \\
AGFA & 0.9 and more & 0.94 & Fit \\
\hline
\end{tabular}

Table 7. Results of the implementation of structural equation model among variables.

\begin{tabular}{lcc}
\hline Model & Standard factor & $\mathrm{T}$ \\
\hline Normative style-conflict management & 0.71 & 7.89 \\
Intuitive style- conflict management & 0.51 & 6.03 \\
Analytical style- conflict management & 0.62 & 7.11 \\
Realistic style- conflict management & 0.74 & 8.91 \\
\hline Chi-square $=37.15 ; \mathrm{df}=24 ; \mathrm{p}=0.00 ;$ RMSEA $=0.052$ & &
\end{tabular}




\section{DISCUSSION}

Negotiation and conflict are concepts associated with many variables and any organization needs strengthening these two variables to reduce problems and increase productivity. The aim of this study is to provide a structural model of the relationship between negotiation and conflict management styles for physical education experts.

One of the objectives of this study was to investigate the relationship between the conflict management and negotiation skills. The results of the structural equation indicate that there is a significant relationship between negotiation skills and conflict management with standardized coefficient 0.89 and significant number 7.45.

The results of this model indicate that improving organizational processes regarding the proper use of negotiation skills and creating a good relationship at the time of negotiation would result in the followings: experts and managers engaged in physical training in educational organizations and centers work with more power and energy and for longer hours. Experts undertake responsibility and do their duties despite the difficulties and problems. They manage the conflicts of the organization towards a positive and productive end and forget about all minor issues that could disrupt the job and lead to negative conflict. And, they would work enthusiastically and enjoy the benefits of the most useful communication in the organization. In fact, useful communication obtained through negotiations and eliminate destructive conflict in the organization can work as a motivational engine in order to create opportunities for people to be creative. Managers in all positions and levels need to curve creative communication through performing the negotiation skill.

The results showed that the application of negotiation styles by experts would be as follows in order of importance from highest to lowest: realistic, normative, analytical and intuitive style. The results of studies conducted by Mirmasoudi (11), Veismoradi (28), Rahimi (18), Torabi (8) and Panahi Kohagh (17) categorized the application of negotiation styles among managers in an order from the most to the least degree of importance and indicate that the style of realism has been the most frequently used style among managers and experts. Friedman test was used to prioritize the negotiation styles and the realistic style ranked at the top of the table. The result of the Friedman test is consistent with this study. Another result of this research shows that there is a linear relationship between the negotiation styles practiced by experts with conflict management. Conflict management strategies among physical education experts can be predicted by selecting the style of negotiation. Also, the results of structural equation modeling indicate that there is a significant relationship between the negotiation and conflict management styles according to standardized coefficients and significant numbers cited in table 7 . The results of this model indicate that if experts use the proper style of negotiation in the communication process with managers and employees, probably the conflicts in the organization will be appropriately managed.

The results of this study indicate that the ratings of conflict management strategies are as follows: solution-focused strategy is in the first priority, the second priority is the control strategy and avoidance strategy takes the third place. The results are consistent with those found in studies conducted by Ghaziani (6), Saatchian (22), Mehri (10) and Deehghan (2). Conducted a studies and the results showed that solution-focused strategy is the dominant conflict management strategy which is used by athletic team trainers and showed that cooperation strategy and avoid approach are respectively the first and the second priorities of conflict management for physical education administrators. On the other hand, the results show no consistency with founding of Aljowazeh (26), and Torabi (25).

Achieving such an outcome could have different reasons. The results show that the experts have the necessary skills to negotiate, therefore such results are predictable because the negotiation strategy is a communicative skill which is ranked under social skills category. Obtaining acceptable results in the negotiations can be achieved by respecting the principles and techniques of communication. If you do not follow the principles of communication, particularly by refusing to consider receivers of the messages, negative results will be achieved. Thus, if the manager knows about the negotiation skill well, but fails to fully understand the spatial and temporal condition of the groups, this would probably lead to increasing the conflict rather than actually reducing it. 
Harji et al. (7) stated that skillful communication depends on using the suitable and efficient ways of communicating with others which is applied by the correct use of materials (in terms of context) and facilitator (in terms of behavior). Sometimes, professionals whose jobs require a special interactive style of communication have encountered problems in terms of relations with others. For example, experts who are active in an advisory role and use consulting styles more likely than others may also experience problem in social relationships.

Communication and negotiation are subcategories of social skills and appropriate social behavior are associated with the interaction context, the role of individuals, their objectives and such characteristics as age, sex, personality and so on. The results of this piece of research indicate that everybody relies on the special style of negotiation and applies the conflict management strategies to a certain ratio, though there is always a dominant style for each person that he found it compatible with his personal traits and his behavioral manner. As the results indicate, most of the physical education experts prefer to apply solution-focused strategy to manage conflict and they adopt the realistic negotiation style in resolving the challenges of their daily work. This style of negotiation and conflict management strategy are very useful, but it does not necessarily mean that one should avoid adopting other methods and styles. Although conflict management strategies are various and dissimilar in terms of application and style, the superiority of one strategy over another has never been proven. The same is true about the negotiation styles and situations and conditions are determining factors for applying one of the strategies and styles. Of course, many other factors could be involved in the decision making process to choose a style and the researchers have tried to recognize some of these factors in this research. Since the physical education experts who are working at the colleges and schools deal with multiple stakeholders, they need to develop the communicative skills and negotiation styles, as well as conflict management strategy. Thus, the results of this study can provide the researchers and managers with the following recommendations:

- To take the cross-training courses to increase the negotiation skills and knowledge.
- To empower managers of the physical education institutes.

- To develop the scientific approach to negotiations.

- To use experts who are skillful and experienced in the principles and techniques of negotiation, communication and conflict management strategies.

- To employ the research and experiences of different countries regarding negotiations. Within and outside of the organization to increase productivity in physical education activities at schools.

In the last part, it is recommended that researchers, who are interested to develop the studies in this field, examine the other factors affecting the conflict management strategies and negotiation styles applied by managers working in the field of physical education.

\section{REFERENCES}

1. Amir KA. Organization and management, the engineering system and contingency measures. Tehran: Publication Hur, 2007.

2. Dehghani H, Hamidi M, Seyf Panahi J. Its five personality traits and ways of dealing with conflict. Sport Management, 2010; (7): 73-92.

3. Farahani. Mohammed Taqi al. The relationship between leadership style and conflict management strategies in managers, Journal of Behavioral Sciences, 2007; 1(1): 86-79.

4. Farrokhi F. the role of managers, July 2008; No: 32 Accessed in: http:// http://www.ensani.ir/fa/content/57921/default.aspx ,(2006).

5. Fisher R. Negotiation power: getting and using influence. Cambridge program on negotiation Books, 1991.

6. Ghaziani. fatemeh, Moudi. mohsen. Comparison of conflict management strategies of physical education office managers based on some demographic characteristics. Annals of Applied Sport Science, 2013; 1(1): 12-18.

7. Harji H, Saunders C, Dixon D. Social skills in interpersonal communication. Translations: Begay and M. Firoz Bakht, Tehran, Publication of Roshd, Third Edition, 2005.

8. Torabi A. The relationship between conflict management styles and strategies of negotiations between the managers of Ahwaz Hospitals. Jentashapir Journal of Health Science, 2010; 2(3): 4656.

9. Hinlh, Tobin. Negotiation techniques. Translation: Shafaei Elahe, Tehran: Publication of Sarghol, 2002.

10. Mehri A, Moharramzadeh M. The relationship between perceived conflict and conflict resolution styles among managers and employees of the General Directorate of Youth and Sport of 
West Azerbaijan province. The Study of Physiology and Sports Management, 2012; (12): 33-43.

11. Mir Masoudi, Syed Kosha. Negotiation Styles and occupational variables executives in urban health centers. Sadra Medical Science Journal, 2014; 2(2): 135-142.

12. Moorhead Gustav, Griffin Patrick . Organizational Behavior, translation: Alvani. Mehdi, Publishing Pearls, Tehran, 2005.

13. Moqimi M. Organization and management: sales management. Terme, Tehran, Second Edition, 2011.

14. Naderian Jahromy, M. Sultan Husseini M. Skills and technical capabilities for athletic directors (index criteria from the perspective of managers). Sports Management Research and Sciences of Motion, 2001; 1(2): 11-18.

15. Nekoeimoghadam M. The relationship between leadership styles and conflict management strategies in the hospital. The Hospital Magazine, 2010; 1(2): 57-65.

16. Oredeina, Afolakemi olasumbo, Mercy Eigbe. Leadership negotiation skill as correlate of university conflict resolution In Nigeria. Procedia - Social and Behavioral Sciences, 2013; 112: 1237-1245.

17. Panahi Kohaqh. The relationship between negotiation styles and effectiveness of the organization in small and medium industries. Thesis, Tehran University, School of Management, 2006. Accessed in . http://etd.ut.ac.ir/thesis/ UTCatalog.

18. Rahimi H, Aghababaei R. Analyzing the relationship between the application of negotiation styles and conflict management strategies in Kashan University of Medical Sciences. Journal of Medical Education, 2012; 5(9): 13-22.

19. Raymond A. Fridman,Simon T. Tidd, Steven C. Currall, James C. Tsai. What goes around come around: the impact of personal conflict style on work conflict and stress, international journal of conflict management, vol. 11:1, pp.32-55. https://doi.org/10.1108/eb022834
20. Rezaeian A. Conflict management and negotiation. Publishing Samt, Tehran, 2005; (1): 140-148.

21. Robbins, Stephen. Principles of management. Translation: Alvani, Mehdi. Second Edition, Tehran: Publications Office of Cultural Studies, 2003

22. Saatchian V. The relationship between emotional intelligence and conflict management strategies and athletic trainers East Azerbaijan province. Sport Management, 2012; (13): 99-113.

23. Shojaei M. Styles of conflict management and communication quality manager - an employee of the sports organizations. Journal of Sport Management and Motor Behavior, 2011; 1(2): 4546

24. Stoner J. Management. Translation: Parsaeian, Ali. Arab, Mohammed. The Office of Cultural Studies, 2003; 2: 929.

25. Torabi A. The relationship leadership style and conflict management in among managers in Lorestans. $7^{\text {th }}$ International Conference of Quality Managers, 2006.

26. Al-jawazheh B. Conflict handling styles and employees commitment at the pharmaceutical companies in Jordan. International Journal of Business and Management, 2015; 10(3): .v10n3p141-151. http://dx.doi.org/10.5539/ijbm

27. Turani, sogand. Relationship public hospital nurses' conflict level and application of negotiation styles by head of Bushehr province. Journal of Qazvin University of Medical Sciences, 2010; 15(2): 68-64.

28. Veismoradi A. Analysis of the impact on the sales negotiation skills styles (case study Chini Kord Company to Kermanshah). Conference Management, Challenges and Solutions, Shiraz. http://www.civilica.com/Printable-ICMM01_0405, (2013).

29. Yu-te. Tu. A cross-cultural comparison of Brazil, Russia, India, and China (BRIC) on negotiation styles. Anthropologist, 2014; 19(2): 457-46. 